\title{
Macrosegregation Caused by Interdendritic Liquid Flow during Solidification of Iron Alloys*
}

\author{
By Hiroyuki NOMURA,** Yoshio TARUTANI*** and Kazumi MORI****
}

\section{Synopsis}

An analysis is given of solute segregation in solidified samples caused by interdendritic mass flow of solute-rich liquid to feed solidification contraction. Calculations are presented for solidification of $\mathbf{F e}-\underline{\mathbf{C}}-\underline{\mathbf{P}}$ ingot with an abrupt change of cross-sectional area. Noticeable solute-depleted bands with sharp peaks are predicted to form in the vicinity of the section of area reduction. The severe segregation peak is calculated to be produced with the large area reduction.

To clarify the mechanism of formation of negative segregation a series of experiments of uni-directional solidification has been done. A clear negative segregation has appeared in the solidified sample. Extent of segregation is larger for phosphorus than carbon. Reasonable agreement of prediction of the model with the experiment has been obtained.

\section{Introduction}

One of the major factors contributing to macrosegregation in steel ingot is fluid flow through dendritic arrays during solidification. The driving force for the fluid flow is liquid-solid shrinkage, as well as solute or thermal gradients in the liquid, and stirring imposed externally on the system. Macrosegregation in steel caused by interdendritic fluid flow has been reported in a number of recent papers. ${ }^{1-5)}$ However, there are unsolved problems left in the mechanism of formation of macrosegregation.

In this paper we examine macrosegregation which results from fluid flow as driven by only solidification contraction. We develop a mathematical model to express the basic mechanism of solute segregation for iron-base alloy. To test the result of model calculations a series of experiments of uni-directional solidfication was undertaken. Melting and solidification of iron were done in the crucible with an abrupt change of cross-sectional area. All of experiments were done with laboratory-size specimens of $\mathrm{Fe}-\underline{\mathrm{C}}-\underline{\mathrm{P}}$ alloys.

Studies of solute segregation caused by interdendritic fluid flow have been previously done by Flemings and coworkers ${ }^{6-8}$ ) for casting of $\mathrm{Al}$ alloys. However, no study has yet been done for the controlled uni-directional solidification of iron-base alloys.

\section{Analysis}

\section{Segregation Pattern}

According to Wray, ${ }^{9)}$ the volume contraction in solidification of iron with $0.1 \% \mathrm{G}$ is about $3.7 \%$.
Greeping flow to feed local shrinkage arises in liquidsolid mushy zone at the solidification front, the velocity being estimated by the following equation. ${ }^{1)}$

$$
\boldsymbol{V}=-\beta /(1-\beta) \cdot \boldsymbol{R}
$$

where, $\boldsymbol{V}$ : interdentritic flow velocity

$\boldsymbol{R}$ : solidification velocity

$\beta$ : parameter concerning solidification shrinkage $\left(=\left(\rho_{\mathrm{S}}-\rho_{\mathrm{L}}\right) / \rho_{\mathrm{S}}\right)$

$\rho_{\mathrm{S}}, \rho_{\mathrm{L}}$ : densities of solid and liquid, respectively

No macrosegregation caused by interdendritic flow occurs when the interdendritic flow velocity $\boldsymbol{V}$ is just equal to that of steady flow required to feed the shrinkage. However, once the steady interdendritic flow is disturbed during solidification, solute mass in the interdendritic liquid volume is not conserved, leading to the formation of macrosegregation in the solidified phase. In this paper, as an example of the case above described, we examine solidification of an ingot sketched in Fig. 1, in which the cross-sectional area is abruptly reduced by the ratio $A_{\mathrm{I}} / A_{\mathrm{II}}$ at $x=0$. In this case of solidification, liquid is forced to flow down through the restricted section (Region I) throughout solidification to feed the much larger section (Region II), and therefore flow velocity at $x=0$ will be much

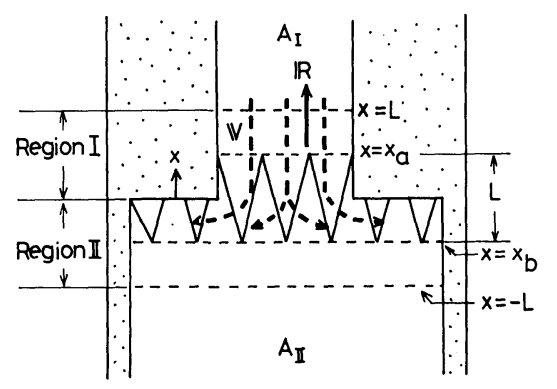

$$
\begin{aligned}
\mathbb{R}: \text { Solidification velocity } \\
\mathbf{V}: \text { Velocity of liquid caused } \\
\\
\text { by volume contraction } \\
A_{I}: \text { Sectional area of region I } \\
A_{I}: \text { Sectional area of region II } \\
L: \text { Length of liquid-solid } \\
\\
\text { layer }
\end{aligned}
$$

Fig. 1. Schematic picture showing interdendritic liquid flow caused by solidification contraction.

* Originally published in Tetsu-to-Hagané, 67 (1981), 80 \& 88, in Japanese; formerly presented to the 96th ISIJ Meeting, October 1978, Toyama University, Takaoka 933. English version received March 26, 1981.

** Formerly Department of Iron and Steel Engineering, Nagoya University. Now at Toyohashi University of Technology, Tenpakucho, Toyohashi 440.

*** Formerly Graduate School, Nagoya University. Now at Sumitomo Central Research Laboratories, Sumitomo Metal Industries, Ltd., Nishinagasu-hondori, Amagasaki 660.

**** Department of Iron and Steel Engineering, Nagoya University, Furo-cho, Chikusa-ku, Nagoya 464. 
larger than that predicted from Eq. (1). A schematic illustration of possible flow behavior is shown in Fig. 1. This flow can produce the local depletion of solute-rich liquid, and thus negative segregation will be induced in the vicinity of the section of area reduction.

\section{Fundamental Equation}

In the ordinary solidification mass flow due to solidification contraction does not sweep the solute out of the interdendritic liquid volume. Solute enrichment produced during this ordinary solidification is described as follows:

a) Equilibrium solidification

$$
c_{\mathrm{L}}=c_{0} /\left\{1-(1-k)\left(1-f_{\mathrm{L}}\right)\right\}
$$

b) Nonequilibrium solidification

$$
c_{\mathrm{L}}=c_{0} f_{\mathrm{L}}^{k-1}
$$

General expressions for solute segregation caused by interdendritic flow of solute-rich liquid will be derived from the following basic conservation equations. ${ }^{1)}$

Consevation of solute mass:

$$
\frac{\partial}{\partial t}(\bar{\rho} \bar{c})=-\nabla \cdot \rho_{\mathrm{L}} f_{\mathrm{L}} C_{\mathrm{L}} \boldsymbol{V}
$$

Conservation of total mass:

$$
\frac{\partial}{\partial t} \bar{\rho}=-\nabla \cdot \rho_{\mathrm{L}} f_{\mathrm{L}} \boldsymbol{V}
$$

where, $\bar{\rho}$ : local average density (of liquid and solid)

$\bar{c}$ : local average concentration (of liquid and solid)

$\rho_{\mathrm{L}}:$ liquid density

$f_{\mathrm{L}}$ : volume fraction of liquid

Solute partition at the liquid-solid interface is described by:

$$
\begin{aligned}
c_{\mathrm{S}} & =k c_{\mathrm{L}} \text { (Equilibrium solidification) } \ldots . . . . \\
c_{\mathrm{S}}^{*} & =k c_{\mathrm{L}} \text { (Nonequilibrium solidification) }
\end{aligned}
$$

where, $c_{\mathrm{S}}$ : concentration in solid phase

$c_{\mathrm{S}}^{*}$ : solid-side concentration at the liquidsolid interface

$k$ : equilibrium partition coefficient

Combination of Eqs. (4) to (7) gives the following relations:

a) Equilibrium solidification

$$
\frac{\partial f_{\mathrm{L}}}{\partial c_{\mathrm{L}}}=-\frac{k+\{1-\beta-k+(1-\beta) \boldsymbol{V} \cdot \nabla T / \varepsilon\} f_{\mathrm{L}}}{(1-k) c_{\mathrm{L}}}
$$

b) Nonequilibrium solidification ${ }^{6-8)}$

$$
\frac{\partial f_{\mathrm{L}}}{\partial c_{\mathrm{L}}}=-(1+\boldsymbol{V} \cdot \nabla T / \varepsilon) \frac{1-\beta}{1-k} \frac{f_{\mathrm{L}}}{c_{\mathrm{L}}}
$$

where, $\varepsilon$ : cooling rate

$\nabla T:$ temperature gradient

In the case of uni-directional solidification as sketched in Fig. 1, thermal gradient exists only in $x$ - direction. The term $\boldsymbol{V} \cdot \nabla T$ in Eqs. (8) and (9) may therefore be simplified to $V_{x}(\partial T / \partial x)$.

\section{Estimation of the Velocity of Liquid Flow}

For the solidification as shown in Fig. 1 three modes may be distinguished in relation to the location of solid-liquid layer.

Mode 1: Dendrite tip $\left(x=x_{a}\right)$ is located in Region II.

Mode 2: Dendrite tip is located in Region I and dendrite root in Region II.

Mode 3: Dendrite root is located in Region I.

For the solidification of Mode 1 and Mode 3, the velocity of interdendritic flow is given by Eq. (1) and solidification is supposed to accompany no macrosegregation. During solidification of Mode 2, however, local flow velocity exceeds that estimated from Eq. (1), and macrosegregation is expected to arise. We begin with derivation of the simplified expression of interdendritic flow velocity.

Region I

Unsolidified liquid must flow down through this restricted region to compensate for solidification contraction. The flow rate at the lowest location of Region I $(x=0)$ may be given by:

$$
V_{x}=-\frac{\beta}{1-\beta} R_{x} \frac{A_{\mathrm{II}}}{A_{\mathrm{I}}}
$$

If $f_{\mathrm{L}}^{\mathrm{N}}$ is taken as the liquid fraction at $x=0$, flow rate at the arbitrary location may be represented by:

$$
V_{x}=-\frac{\beta}{1-\beta} R_{x}\left(\frac{A_{\mathrm{II}}-A_{\mathrm{I}}}{A_{\mathrm{I}}} \frac{f_{\mathrm{L}}^{\mathrm{N}}}{f_{\mathrm{L}}}+1\right)
$$

Substitution of $f_{\mathrm{L}}^{\mathbb{N}}=f_{\mathrm{L}}-\alpha$ into Eq. (11) leads to:

$$
V_{x}=-\frac{\beta}{1-\beta} R_{x}\left(\begin{array}{cc}
A_{\mathrm{II}}-A_{\mathrm{I}} & f_{\mathrm{L}}-\alpha \\
A_{\mathrm{I}} & f_{\mathrm{L}}
\end{array}\right)
$$

where, $\alpha=|x| / L$.

Region II

Flow from the upper region is supposed to occur towards the corner in Region II as pictured in Fig. 1, and uniform flow across mushy zone is not considered to occur. A simplified model in which flow rate in this region decreases with the decrease of liquid fraction is employed here:

$$
V_{x}=-\frac{\beta}{1-\beta} R_{x} \frac{A_{\mathrm{II}}}{A_{\mathrm{I}}} \frac{f_{\mathrm{L}}}{f_{\mathrm{L}}^{\mathrm{N}}}
$$

This equation is consistent with Eq. (1) for $f_{\mathrm{L}}=f_{\mathrm{L}}^{\mathrm{N}}$, the liquid fraction at the section of area reduction. Substituting $f_{\mathrm{L}}^{\mathrm{N}}=f_{\mathrm{L}}+\alpha$ into Eq. (13) yields :

$$
V_{x}=-\frac{\beta}{1-\beta} R_{x} \frac{A_{\mathrm{II}}}{A_{\mathrm{I}}} \frac{f_{\mathrm{L}}}{f_{\mathrm{L}}+\alpha}
$$

\section{4. $\delta-\gamma$ Transformation during Solidification}

If iron contains carbon of 0.09 to $0.53 \%, \delta-\gamma$ transformation occurs during solidification as suggested from $\mathrm{Fe}-\mathrm{C}$ phase diagram. On the basis of the cal-

* The derivation of Eq. (8) was shown in Appendix. 
culation by Schwerdtfeger ${ }^{10)}$ carbon concentration of liquid phase is considered to be kept at $0.53 \%$ during transformation of $\delta$-phase $(\mathrm{C}=0.09 \%)$ into $\gamma$-phase $(\mathrm{C}=0.17 \%)$. Consequently,

$$
0.53 \xi+0.09(1-\xi)=0.53 \xi^{\prime}+0.17\left(1-\xi^{\prime}\right) \ldots
$$

This is simplified to:

$$
\xi^{\prime}=(11 \xi-2) / 9
$$

where, $\xi$ : liquid fraction at the beginning of $\delta-\gamma$ transformation

$\xi^{\prime}$ : liquid fraction at the end of $\delta-\gamma$ transformation.

\section{Derivation of Equations Describing Solute Redistribu- tion}

Combination of Eqs. (2) to (16) gives basic relations representing solute redestribution after solidification.

\section{Redistribution of Carbon}

Equilibrium solidification model is used.

\section{(1) Region I}

Solidification of Mode 2 proceeds during the early stage of solidification and Mode 3 during the late stage. Further classification is needed according as whether or not $\delta-\gamma$ transformation occurs.

(i) The transformation does not occur during solidification of Mode 2 (Case A).

(ii) The transformation begins to occur in solidification of Mode 2, and continues to occur throughout solidification of Mode 2 (Case B).

(iii) The transformation begins to occur in solidification of Mode 2, and completes in solidification of Mode 2 (Case G).

Case A

Single phase of $\delta$ or $\gamma$ precipitates during solidification of Mode 2. Substitution of Eq. (12) into Eq. (8) gives:

$$
\frac{\partial f_{\mathrm{L}}}{\partial c_{\mathrm{L}}}=\frac{k+\left\{1-\beta-k+\beta\left(\frac{A_{\mathrm{II}}-A_{\mathrm{I}}}{A_{\mathrm{I}}} \cdot \frac{f_{\mathrm{L}}-\alpha}{f_{\mathrm{L}}}+1\right)\right\} f_{\mathrm{L}}}{(1-k) c_{\mathrm{L}}}
$$

Replacing $\beta\left(A_{\mathrm{II}}-A_{\mathrm{I}}\right) / A_{\mathrm{I}}$ with $P$ and integrating Eq. (17) from the initial condition, $c_{\mathrm{L}}=c_{0}, f_{\mathrm{L}}=1$ to $c_{\mathrm{L}}, f_{\mathrm{L}}$ yield:

$$
\int_{1}^{f_{\mathrm{L}}} \frac{d f_{\mathrm{L}}}{(1-k+P) f_{\mathrm{L}}+k-\alpha P}=-\frac{1}{1-k} \int_{c_{0}}^{c_{\mathrm{L}}} \frac{d c_{\mathrm{L}}}{c_{\mathrm{L}}}
$$

Hence:

$$
\begin{aligned}
& c_{\mathrm{L}}=c_{0}\left(\begin{array}{c}
1+\frac{k-\alpha P}{1-k+P} \\
f_{\mathrm{L}}+\frac{k-\alpha P}{1-k+P}
\end{array}\right)^{(1-k / 1-k+P)} \\
& c_{\mathrm{S}}=k c_{\mathrm{L}} \quad \ldots \ldots \ldots \ldots \ldots \ldots \ldots \ldots \ldots \ldots \ldots \ldots \ldots \ldots \ldots \ldots \ldots \ldots \ldots
\end{aligned}
$$

As partition coefficients, $k_{\delta}$ and $k_{\gamma}$ are used for solidified phase of $\delta$ and $\gamma$, respectively. Taking $\alpha$ as the liquid fraction at the end of solidification of Mode 2, Eqs. (19) and (6) are to be combined to give the solute concentration of solidified phase:

$$
\begin{aligned}
c_{\mathrm{S}}^{\mathrm{E}} & =\alpha c_{\mathrm{L}, f_{\mathrm{L}}=\alpha}+(1-\alpha) c_{\mathrm{S}, f_{\mathrm{L}}=\alpha} \\
& =c_{0}\{(1-k) \alpha+k\}\left(\frac{1+q}{\alpha+q}\right)^{r} .
\end{aligned}
$$

where,

$$
\begin{aligned}
& q=\frac{k-\alpha P}{1-k+P} \\
& r=\frac{1-k}{1-k+P}
\end{aligned}
$$

\section{Case B}

At the end of solidification of Mode 2, $\delta-\gamma$ transformation does not complete and three phases of $\delta, \gamma$ and liquid coexist. Solute mass in solid-liquid volume element is conserved till the final stage of solidification of Mode 3. Therefore the final concentration of the solidified phase is given by:

$$
c_{\mathrm{S}}^{\mathrm{E}}=0.53 \xi+0.09(1-\xi) \text {. }
$$

where $\xi$ is equal to $f_{\mathrm{L}}$ in Eq. (19) for $c_{\mathrm{L}}=0.53$.

Case $\mathrm{C}$

Equation (18) is to be integrated between the limits, $c_{\mathrm{L}}=0.53$ at $f_{\mathrm{L}}=\xi^{\prime}$ and $c_{\mathrm{L}}, f_{\mathrm{L}}$ :

$$
c_{\mathrm{L}}=0.53\left(\begin{array}{c}
\xi^{\prime}+q_{r} \\
f_{\mathrm{L}}+q_{\gamma}
\end{array}\right)^{r_{r}}
$$

Final concentration is represented by the use of the concentration at the end of solidification of Mode 2 $\left(f_{\mathrm{L}}=\alpha\right)$.

$$
\begin{aligned}
c_{\mathrm{S}}^{\mathrm{E}} & =\alpha c_{\mathrm{L}, f_{\mathrm{L}=\alpha}}+(1-\alpha) c_{\mathrm{S}, f_{\mathrm{L}}=\alpha} \\
& =0.53\left\{\left(1-k_{\gamma}\right) \alpha+k_{\gamma}\right\}\left(\frac{\xi^{\prime}+q_{\gamma}}{\alpha+q_{\gamma}}\right)^{r_{\gamma}}
\end{aligned}
$$

where $q_{r}$ and $r_{r}$ are $q$ and $r$ for $k=k_{r}$, respectively.

(2) Region II

In this region solidification of Mode 1 occurs in the early stage of solidification and Mode 2 in the late stage. Further classification is done according to the occurrence of $\delta-\gamma$ transformation.

(i) The transformation does not occur during solidification of Mode 1.

(i-a) The transformation does not occur till the end of solidification of Mode 2 (Case D).

(i-b) The transformation begins to occur in solidification of Mode 2, but does not complete by the end of solidification (Case $\mathrm{E}$ ).

(i-c) The transformation begins to occur in solidification of Mode 2, and completes during solidification (Case F).

(ii) The transformation occurs during solidification of Mode 1.

(ii-a) The transformation does not complete by the end of solidification of Mode 2 (Case G).

(ii-b) The transformation completes in solidification of Mode 2( Case $\mathrm{H}$ ).

(ii-c) The transformation completes in solidification of Mode 1 (Case I).

Case D

Substitution of Eq. (14) into Eq. (8) gives the basic equation for the analysis of solidification of Mode 2 in Region II: 


$$
\frac{\partial f_{\mathrm{L}}}{\partial c_{\mathrm{L}}}=\frac{k+\left(1-\beta-k+\beta \frac{A_{\mathrm{II}}}{A_{\mathrm{I}}} f_{\mathrm{L}}+\alpha\right) f_{\mathrm{L}}}{(1-k) c_{\mathrm{L}}}
$$

The concentration in liquid phase at the end of solidification of Mode 1 is given from Eq. (2) by letting $f_{\mathrm{L}}=1-\alpha$ :

$$
c_{\mathrm{L}}=c_{0} /\{1-(1-k) \alpha\}
$$

Integrating Eq. (24) between the limits, $c_{\mathrm{L}}$ at $f_{\mathrm{L}}=1-$ $\alpha$ and $c_{\mathrm{L}}, f_{\mathrm{L}}$ provides:

$$
\begin{aligned}
& \int_{1-\alpha}^{f_{\mathrm{L}}} d f_{\mathrm{L}} /\left\{k+\left(1-\beta-k+\beta \frac{A_{\mathrm{II}}}{A_{\mathrm{I}}} \frac{f_{\mathrm{L}}}{f_{\mathrm{L}}+\alpha}\right) f_{\mathrm{L}}\right\} \\
& =-\frac{1}{1-k} \int_{c_{0} /\{1-(1-k) \alpha\}}^{c_{\mathrm{L}}} \frac{d c_{\mathrm{L}}}{c_{\mathrm{L}}}
\end{aligned}
$$

From Eq. (26), $c_{\mathrm{L}, f_{\mathrm{L}}=0}$ is calculated to yield the solute concentration at the end of solidification:

$$
c_{\mathrm{S}}^{\mathrm{E}}=k c_{\mathrm{L}, f_{\mathrm{L}}=0}
$$

Case E

Equation (24) is integrated from $c_{\mathrm{L}}, f_{\mathrm{L}}=1-\alpha$ to $c_{\mathrm{L}}, f_{\mathrm{L}}$, to give the liquid fraction $\xi$ at $c_{\mathrm{L}}=0.53 \%$.

The solute concentration of solidified phase is given by Eq. (21) because solute mass is conserved during $\delta-\gamma$ transformation.

Case F

The liquid fraction $\xi$ at the beginning of $\delta-\gamma$ transformation may be predicted in the same manner as described in Case E. Equation (16) gives $\xi^{\prime}$, the liquid fraction at the end of $\delta-\gamma$ transformation. Integration of Eq. (24) is done between $c_{\mathrm{L}}=0.53 \%$ at $f_{\mathrm{L}}=\xi^{\prime}$ and $c_{\mathrm{L}}, f_{\mathrm{L}}$ to give $c_{\mathrm{L}, f_{\mathrm{L}}=0}$. Final concentration is calculated by the use of Eq. (27).

Case G

Solute mass at the beginning of $\delta-\gamma$ transformation is conserved till the final stage of solidification. Therefore,

$$
c_{\mathrm{S}}^{\mathrm{E}}=c_{0}
$$

Case $\mathrm{H}$

From Eq. (2) liquid fraction $\xi$ is expressed as:

$$
\xi=\frac{1}{1-k_{\delta}}\left(\frac{c_{0}}{0.53}-k_{\delta}\right)
$$

Equation (24) is integrated between $c_{\mathrm{L}}=0.53 \%$ at $f_{\mathrm{L}}=\xi^{\prime}$ (given by Eq. (16)) and $c_{\mathrm{L}}, f_{\mathrm{L}}$ to give $c_{\mathrm{L}, f_{\mathrm{L}}=0}$. One has final concentration from Eq. (27).

\section{Case I}

The liquid concentration at the end of solidification of Mode 1 is predicted from Eq. (25) by letting $k=k_{r}$. Integration of Eq. (24) is done for the range of solidification of Mode 2. Then one can give the concentration of solidified phase from Eq. (27) in the same manner as described in Case $\mathrm{H}$.

\section{Redistribution of Phosphorus}

Since diffusion coefficient of phosphorus in the solidified phase is considered to be small, nonequilibrium solidification model should be used. Accordingly a simple mass balance equation like Eq. (15) for carbon does not hold for phosphorus. Enrichment of phosphorus in liquid is considered to be done according to Eq. (3) or Eq. (9) with $k=k_{\delta}$ for the range of $\delta$ precipitation and $k_{\gamma}$ after the beginning of $\delta-\gamma$ transformation. Thus in the following analysis a same manner of formulation is applied each for Cases B and C, Cases E and F, and Cases G, H and I.

(1) Region 1

Case A

Substitution of Eq. (9) into Eq. (12) yields :

$$
\frac{\partial f_{\mathrm{L}}}{\partial c_{\mathrm{L}}}=-\left(\frac{1-\beta}{1-k}\right)\left\{1+\frac{\beta}{1-\beta}\left(\frac{A_{\mathrm{II}}-A_{\mathrm{I}}}{A_{\mathrm{I}}} \frac{f_{\mathrm{L}}-\alpha}{f_{\mathrm{L}}}+1\right)\right\} \frac{f_{\mathrm{L}}}{c_{\mathrm{L}}}
$$

Equation (30) is to be integrated between $c_{0}, f_{\mathrm{L}}=1$ and $c_{\mathrm{L}}, f_{\mathrm{L}}$ :

$$
\int_{1}^{f_{\mathrm{L}}} \frac{d f_{\mathrm{L}}}{(1+P) f_{\mathrm{L}}-\alpha P}=-\frac{1}{1-k} \int_{c_{0}}^{c_{\mathrm{L}}} \frac{d c_{\mathrm{L}}}{c_{\mathrm{L}}}
$$

Liquid concentration is given as follows:

$$
c_{\mathrm{L}}=c_{0}\left(\frac{1-s}{f_{\mathrm{L}}-s}\right)^{t}
$$

where, $\quad s=\alpha P /(1+P)$

$$
t=(1-k) /(1+P)
$$

The solute mass at the end of solidification of Mode 2 $\left(f_{\mathrm{L}}=\alpha\right)$ is conserved throughout the subsequent process. Hence the concentration after solidification is given by:

$$
c_{\mathrm{S}}^{\mathrm{E}}=\alpha c_{0}\left(\frac{1-s}{\alpha-s}\right)^{t}+\int_{\alpha}^{1} c_{\mathrm{S}}^{*} d f_{\mathrm{L}}
$$

Combining Eqs. (7), (32) and (33) gives:

$$
c_{\mathrm{S}}^{\mathrm{E}}=\alpha c_{0}\left(\frac{1-s}{\alpha-s}\right)^{t}+\frac{k(1-s)}{1-t}\left\{1-\left(\frac{1-s}{\alpha-s}\right)^{t-1}\right\}
$$

Case B, Case C

The expression for final concentration is:

$$
c_{\mathrm{S}}^{\mathrm{E}}=\int_{\xi}^{1} k_{\delta} c_{\mathrm{L}, f_{\mathrm{L}} \geq \xi} d f_{\mathrm{L}}+\int_{\alpha}^{\xi} k_{\gamma} c_{\mathrm{L}, \alpha<f_{\mathrm{L}}<\xi} d f_{\mathrm{L}}+\alpha c_{\mathrm{L}, f_{\mathrm{L}}=\alpha}
$$

Concentration $c_{\mathrm{L}, f_{\mathrm{L}} \geq \xi}$ is calculated from Eq. (32) by letting $t=t_{\delta}$, while $c_{\mathrm{L}, \alpha<f_{\mathrm{L}}<\xi}$ is obtained by integrating Eq. (31) from $c_{\mathrm{L}}=c_{0}\{(1-s) /(\xi-s)\}^{t_{o}}, f_{\mathrm{L}}=\xi$ to $c_{\mathrm{L}}$, $f_{\mathrm{L}}$;

$$
\int_{\xi}^{f_{\mathrm{L}}} \frac{d f_{\mathrm{L}}}{(1+P) f_{\mathrm{L}}-\alpha P}=-\frac{1}{1-k_{r}} \int_{c_{0}\left(\begin{array}{l}
1-s \\
\xi-s
\end{array}\right)^{t_{\delta}}}^{c_{\mathrm{L}}} \frac{d c_{\mathrm{L}}}{c_{\mathrm{L}}}
$$

This can be simplified to

$$
c_{\mathrm{L}, \alpha<f_{\mathrm{L}}<\xi}=c_{0}\left(\frac{1-s}{\xi-s}\right)^{t_{\hat{o}}}\left(\frac{\xi-s}{f_{\mathrm{L}}-s}\right)^{t_{\gamma}}
$$

Thus Eq. (35) leads to:

$$
\begin{aligned}
c_{\mathrm{S}}^{\mathrm{E}}= & k_{\delta} c_{0} \int_{\xi}^{1}\left(\frac{1-s}{f_{\mathrm{L}}-s}\right)^{t_{\delta}} d f_{\mathrm{L}}+c_{0}\left(\frac{1-s}{\xi-s}\right)^{t_{\delta}} \\
& \times\left\{k_{\gamma} \int_{\alpha}^{\xi}\left(\frac{\xi-s}{f_{\mathrm{L}}-s}\right)^{t_{\gamma}} d f_{\mathrm{L}}+\alpha\left(\frac{\xi-s}{\alpha-s}\right)^{t_{\gamma}}\right\} \\
= & k_{\delta} c_{0} \frac{1-s}{1-t_{\delta}}\left\{1-\left(\frac{\xi-s}{1-s}\right)^{1-t_{\delta}}\right\}+c_{0}\left(\frac{1-s}{\xi-s}\right)^{t_{\delta}} \\
& \times\left[\frac{\xi-s}{1-t_{\delta}} k_{\gamma}\left\{1-\left(\frac{\alpha-s}{\xi-s}\right)^{1-t_{\gamma}}\right\}+\alpha\left(\frac{\xi-s}{\alpha-s}\right)^{t_{\gamma}}\right]
\end{aligned}
$$




\section{(2) Region II}

Case D

Combining Eqs. (9) and (14) gives:

$$
\frac{\partial f_{\mathrm{L}}}{\partial c_{\mathrm{L}}}=-\left(\frac{1-\beta}{1-k}\right)\left\{1+\frac{\beta}{1-\beta} \cdot \frac{A_{\mathrm{II}}}{A_{\mathrm{I}}} \cdot \frac{f_{\mathrm{L}}}{f_{\mathrm{L}}+\alpha}\right\} \frac{f_{\mathrm{L}}}{c_{\mathrm{L}}} \ldots
$$

The concentration at the end of Case $1\left(f_{\mathrm{L}}=1-\alpha\right)$ is:

$$
c_{\mathrm{L}}=c_{0}(1-\alpha)^{k-1}
$$

Integration of Eq. (39) between $c_{\mathrm{L}}$ at $f_{\mathrm{L}}=1-\alpha$ (Eq. $(40))$ and $c_{\mathrm{L}}, f_{\mathrm{L}}$ provides:

$$
\begin{gathered}
\int_{1-\alpha}^{f_{\mathrm{L}}} \frac{f_{\mathrm{L}}+\alpha}{\left(1-\beta+\beta \frac{A_{\mathrm{II}}}{A_{\mathrm{I}}}\right) f_{\mathrm{L}}^{2}+\alpha(1-\beta) f_{\mathrm{L}}} d f_{\mathrm{L}} \\
=-\frac{1}{1-k} \int_{c_{0}(1-\alpha)^{k-1}}^{c_{\mathrm{L}}} \frac{d c_{\mathrm{L}}}{c_{\mathrm{L}}} \ldots \ldots \ldots \ldots \ldots \ldots \ldots \ldots \ldots \ldots \ldots
\end{gathered}
$$

Rearranging, one has:

$$
\begin{aligned}
c_{\mathrm{L}}= & c_{0}(1-\alpha)^{\frac{\beta}{1-\beta}(1-k)} \\
& \times\left\{\frac{(P+1) f_{\mathrm{L}}+\alpha(1-\beta)}{(P+1)(1-\alpha)+\alpha(1-\beta)}\right\}^{\frac{(P+\beta)(1-k)}{(P+1)(1-\beta)}} / f_{\mathrm{L}}^{1-k}
\end{aligned}
$$

The solute concentration after solidification is composed of the following two terms:

$$
\begin{aligned}
& c_{\mathrm{S}}^{\mathrm{E}}=k c_{0}\left\{\int_{1-\alpha}^{1} f_{\mathrm{L}}^{k-1} d f_{\mathrm{L}}+(1-\alpha)^{\frac{\beta}{1-\beta}(1-k)}\right. \\
& \times \int_{0}^{1-\alpha}\left\{\frac{(P+1) f_{\mathrm{L}}+\alpha(1-\beta)}{(P+1)(1-\alpha)+\alpha(1-\beta)}\right\}^{\frac{(P+\beta)(1-k)}{(P+1)(1-\beta)}} \\
& \left.\times f_{\mathrm{L}}{ }^{-1-k}{ }^{1-\beta} d f_{\mathrm{L}}\right\}
\end{aligned}
$$

Case E, Case F

Final concentration, $c_{\mathrm{S}}^{\mathrm{E}}$ is given by:

$$
\begin{aligned}
c_{\mathrm{S}}^{\mathrm{E}}= & \int_{1-\alpha}^{1} k_{\delta} c_{0} f_{\mathrm{L}}^{k_{\delta}-1} d f_{\mathrm{L}}+\int_{\xi}^{1-\alpha} k_{\delta} c_{\mathrm{L}, \xi<f_{\mathrm{L}} \leq 1-\alpha} d f_{\mathrm{L}} \\
& +\int_{0}^{\xi} k_{\gamma} c_{\mathrm{L}, 0<f_{\mathrm{L}} \leq \xi} d f_{\mathrm{L}} \ldots \ldots \ldots \ldots \ldots \ldots \ldots \ldots \ldots \ldots \ldots \ldots \ldots \ldots \ldots \ldots \ldots \ldots \ldots \ldots \ldots
\end{aligned}
$$

Equation (42) can be used for $c_{\mathrm{L}, \xi<f_{\mathrm{L}} \leq 1-\alpha}$, while $c_{\mathrm{L}, 0<f_{\mathrm{L}}<\xi}$ is given by integrating Eq. (39) as follows:

$$
\begin{aligned}
& \int_{\xi}^{f_{\mathrm{L}}} \frac{f_{\mathrm{L}}+\alpha}{\left(1-\beta+\beta \frac{A_{\mathrm{II}}}{A_{\mathrm{I}}}\right) f_{\mathrm{L}}^{2}+\alpha(1-\beta) f_{\mathrm{L}}} d f_{\mathrm{L}} \\
& \quad=-\frac{1}{1-k_{r}} \int_{c_{\mathrm{L}}}^{c_{\mathrm{L}}} \frac{d c_{\mathrm{L}}}{c_{\mathrm{L}}} \ldots \ldots \ldots \ldots \ldots \ldots \ldots \ldots \ldots \ldots \ldots \ldots \ldots \ldots
\end{aligned}
$$

where, $c_{\mathrm{L}}^{\prime}$ is obtained from Eq. (42) by substituting $f_{\mathrm{L}}=\xi$.

$$
\begin{aligned}
c_{\mathrm{L}}^{\prime}= & c_{0}(1-\alpha)^{\frac{\beta}{1-\beta}\left(1-k_{\delta}\right)} \\
& \times\left[\frac{(P+1) \xi+\alpha(1-\beta)}{(P+1)(1-\alpha)+\alpha(1-\beta)}\right]^{(P+\beta)\left(1-k_{\delta}\right)} / \frac{1-k_{\delta}}{(P+1)(1-\beta)} / \xi^{1-\beta}
\end{aligned}
$$

Combination of Eqs. (45) and (46) yields:

$$
c_{\mathrm{L}, 0<f_{\mathrm{L}} \leq \xi}=c_{\mathrm{L}}^{\prime}\left(\frac{\xi}{f_{\mathrm{L}}}\right)^{1-k_{\gamma}}\left[\frac{(P+1) f_{\mathrm{L}}+\alpha(1-\beta)}{(P+1) \xi+\alpha(1-\beta)}\right]^{\frac{(P+\beta)\left(1-k_{\gamma}\right)}{(P+1)(1-\beta)}}
$$

The final concentration of solidified phase is described by:

$$
\begin{aligned}
c_{\mathrm{S}}^{\mathrm{E}}= & c_{0}\left[1-(1-\alpha)^{k_{\delta}}+k_{\delta}(1-\alpha)^{\frac{\beta}{1-\beta}\left(1-k_{\delta}\right)}\right. \\
& \times \int_{\xi}^{1-\alpha}\left\{\frac{(P+1) f_{\mathrm{L}}+\alpha(1-\beta)}{(P+1)(1-\alpha)+\alpha(1-\beta)}\right\}^{\frac{(P+\beta)(1-\beta)}{(P+1)(1-\beta)}} / f_{\mathrm{L}} \frac{1-k_{\delta}}{1-\beta} \\
& \times d f_{\mathrm{L}}+k_{r}\left(\frac{c_{\mathrm{L}}^{\prime}}{c_{0}}\right) \int_{0}^{\xi}\left(\frac{\xi}{f_{\mathrm{L}}}\right)^{\frac{1-k_{\gamma}}{1-\beta}} \\
& \left.\times\left\{\frac{(P+1) f_{\mathrm{L}}+\alpha(1-\beta)}{(P+1) \xi+\alpha(1-\beta)}\right\}^{\frac{(P+\beta)\left(1-k_{r}\right)}{(P+1)(1-\beta)}} d f_{\mathrm{L}}\right] \ldots \ldots . .(48)
\end{aligned}
$$

\section{Case G, Case H, Case I}

Concentration of solidified phase before the beginning of $\delta-\gamma$ transformation in solidification of Mode 1 is given by:

$$
c_{\mathrm{S}, \xi \leq f_{\mathrm{L}} \leq 1}=\int_{\xi}^{1} k_{\delta^{\prime}} c_{0} f_{\mathrm{L}}^{k_{\tilde{\delta}}-1} d f_{\mathrm{L}}=c_{0}\left(1-\xi^{k_{\hat{\delta}}}\right)
$$

Concentration after the beginning of $\delta-\gamma$ transformation is:

$$
\begin{aligned}
c_{\mathrm{S}, 1-\alpha \leq f_{\mathrm{L}} \leq \xi} & =c_{0} \xi^{k_{\delta}-1} \int_{1-\alpha}^{\xi} k_{r}\left(\frac{f_{\mathrm{L}}}{\xi}\right)^{k_{\gamma}-1} d f_{\mathrm{L}} \\
& =c_{0}\left\{\xi^{k_{\hat{o}}}-\xi^{k_{\delta}-k_{r}}(1-\alpha)^{k_{r}}\right\} \ldots \ldots \ldots . . .
\end{aligned}
$$

For solidification of Mode 2, liquid concentration is obtained by integrating Eq. (39) between $c_{\mathrm{L}}=c_{0} \xi^{k_{\tilde{\sigma}}-k_{\gamma}}$ $\times(1-\alpha)^{k \gamma-1}, f_{\mathrm{L}}=1-\alpha$ and $c_{\mathrm{L}}, f_{\mathrm{L}}$ :

$$
\begin{aligned}
c_{\mathrm{L}}= & c_{0} \xi^{k_{\delta}-k_{\gamma}}(1-\alpha)^{k_{r}-1}\left(\frac{1-\alpha}{f_{\mathrm{L}}}\right)^{\frac{1-k_{r}}{1-\beta}} \\
& \times\left\{\frac{(P+1) f_{\mathrm{L}}+\alpha(1-\beta)}{(P+1)(1-\alpha)+\alpha(1-\beta)}\right\}^{\frac{(P+\beta)\left(1-k_{r}\right)}{(P+1)(1-\beta)}}
\end{aligned}
$$

Combining above equations, one has:

$$
\begin{aligned}
c_{\mathrm{S}}^{\mathrm{E}}= & c_{0}\left[1-\xi^{k_{\tilde{\delta}}-k_{\gamma}}(1-\alpha)^{k_{\gamma}}+k_{\gamma} \xi^{k_{\delta}-k_{\gamma}}(1-\alpha)^{k_{\gamma}-1}\right. \\
& \times \int_{0}^{1-\alpha}\left(\frac{1-\alpha}{f_{\mathrm{L}}}\right)^{\frac{1-k_{\gamma}}{1-\beta}} \\
& \left.\times\left\{\frac{(P+1) f_{\mathrm{L}}+\alpha(1-\beta)}{(P+1)(1-\alpha)+\alpha(1-\beta)}\right\}^{\frac{(P+\beta)\left(1-k_{\gamma}\right)}{(P+1)(1-\beta)}} d f_{\mathrm{L}}\right] \ldots
\end{aligned}
$$

\section{Results of Calculation}

Figures 2 to 4 show typical examples of calculated segregation of carbon and phosphorus in solidified ingots. Figure 2, shows a plot of carbon distribution along $x$-axis for several values of area ratio varied as parameters. The classification based on the occurrence of $\delta-\gamma$ transformation is also written in the figures. Severe carbon-poor bands are predicted to appear at the section of area reduction. From the figure solute depletion is indicated to become more noticeable with increase of $A_{\mathrm{II}} / A_{\mathrm{I}}$. 
The effect of change of area ratio $A_{\mathrm{II}} / A_{\mathrm{I}}$ on segregation of phosphorus is shown in Fig. 3, in which a similar effect as seen in Fig. 2 is suggested. The segregation of phosphorus at the section of area reduction is calculated to be more noticeable than that of carbon, which is attributable to the difference in the value of partition ratio.

Figure 4 shows the influence of carbon content on phosphorus segregation. A negligible effect is seen in the range of 0.1 to $0.3 \% \mathrm{C}$. This indicates that whether or not $\delta-\gamma$ transformation occurs and the period of occurrence of the transformation exert no remarkable influence on phosphorus segregation.

\section{Experimental Method}

In order to test the validity of the present analysis, a series of experiments has been done. Figure 5 illustrates the experimental apparatus. Uni-directional solidification was achieved by end-cooling in com-

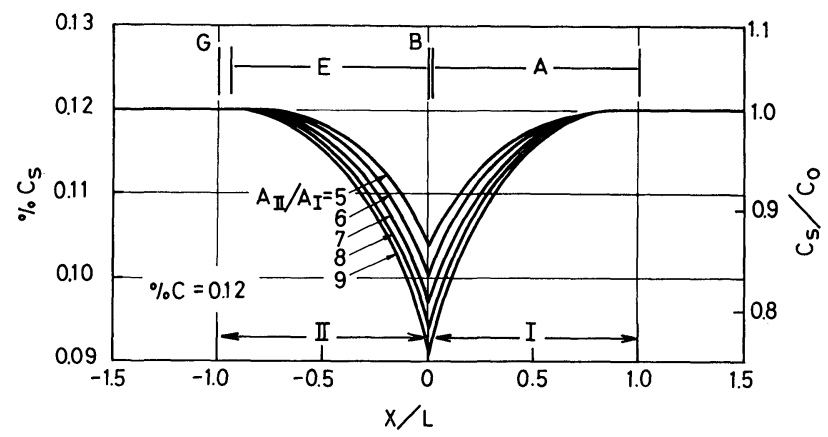

Fig. 2. Calculated concentration distribution of carbon in solidified specimens.

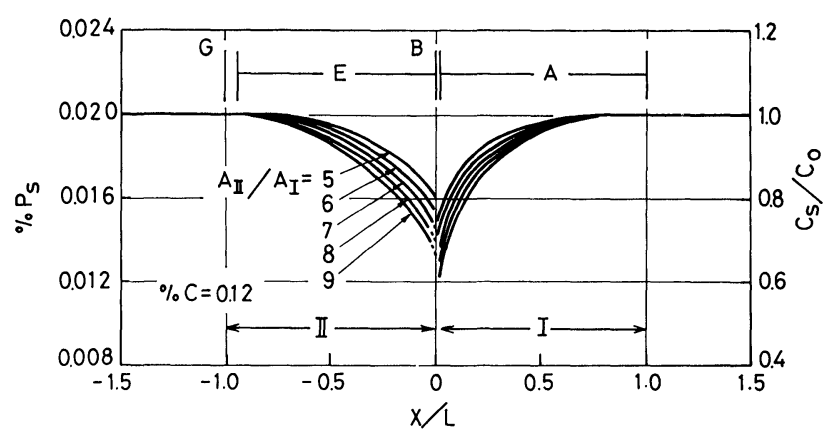

Fig. 3. Calculated concentration distribution of phosphorus in solidified specimens.

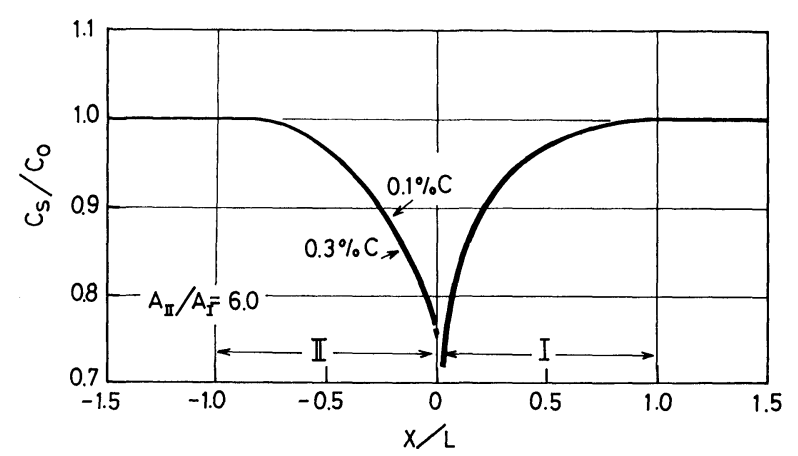

Fig. 4. Calculated concentration distribution of phosphorus in solidified specimens. bination with progressive withdrawal of the induction heating coil activated by a $15 \mathrm{~kW} 100 \mathrm{kHz}$ generator. ${ }^{11)}$ Figure 6 shows the arrangement of crucible which is composed of two magnesia pipes, internal diameter being $30 \mathrm{~mm}$ and $10 \mathrm{~mm}$, respectively. The crucible was designed so that the solidification mode as demonstrated in Fig. 1 might be realized. Region I and Region II are contained in the neck portion and the bottom portion, respectively.

Weight of the iron specimen used in each experiment was $380 \mathrm{~g}$. The initial composition of the specimen was $\mathrm{C}: 0.09 \sim 0.25 \%$, P: $0.013 \sim 0.020 \%$ and $\mathrm{Al}: 0.01 \%$. Solidification experiments were done for the two rates of withdrawal of the induction coil (8 and $12 \mathrm{~mm} / \mathrm{min}$ ). Temperature measurements during solidification were done to determine

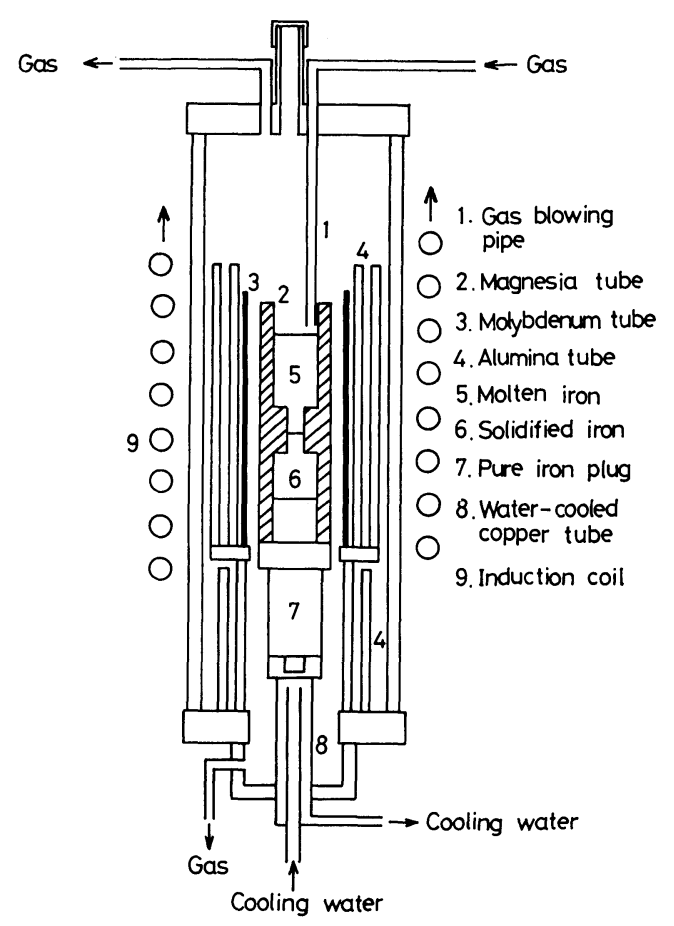

Fig. 5. Experimental apparatus.

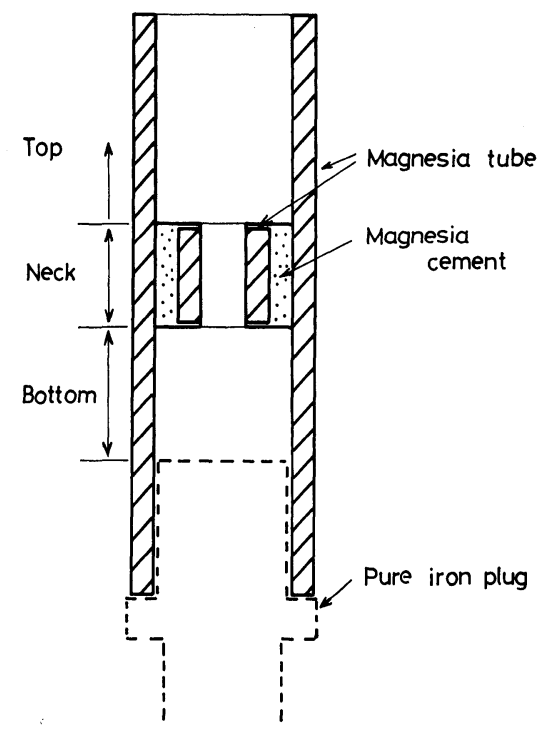

Fig. 6. Arrangement of magnesia tube and iron plug. 


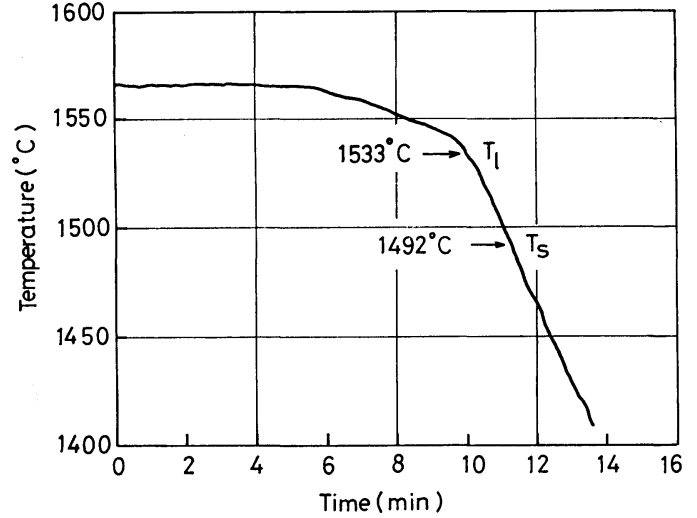

Fig. 7. A cooling curve during solidification (coil speed: $12 \mathrm{~mm} / \mathrm{min}$ ).

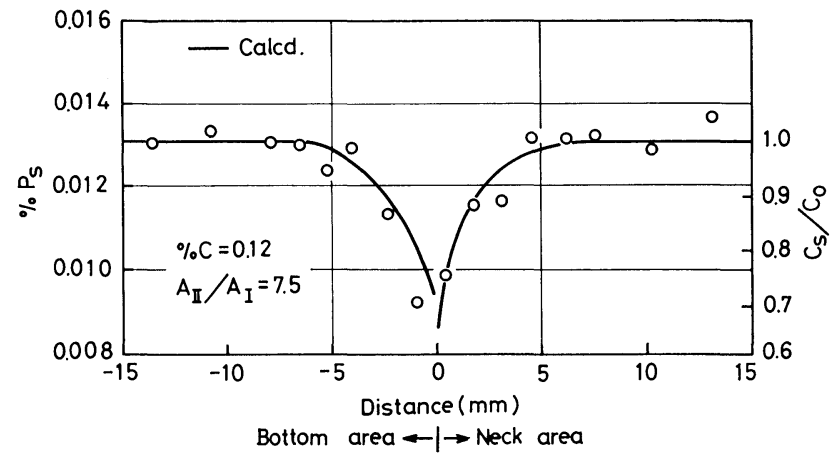

Fig. 8. Concentration distribution of phosphorus in a solidified specimen (coil speed: $8 \mathrm{~mm} / \mathrm{min}$ ).

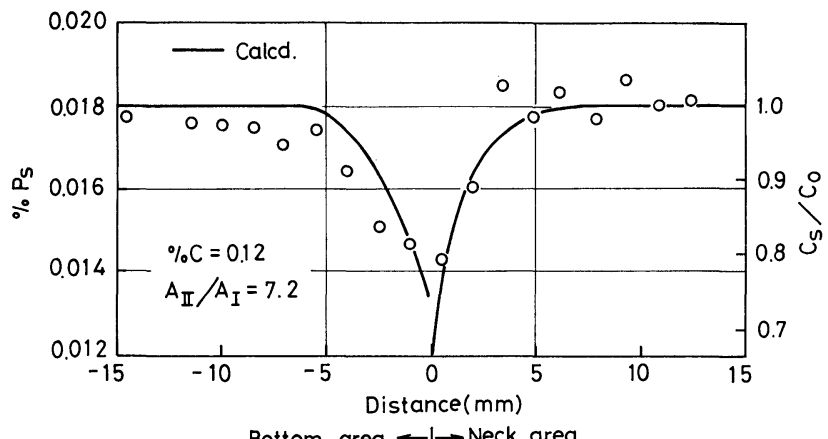

Fig. 9. Concentration distribution of phosphorus in a solidified specimen (coil speed: $12 \mathrm{~mm} / \mathrm{min}$ ).

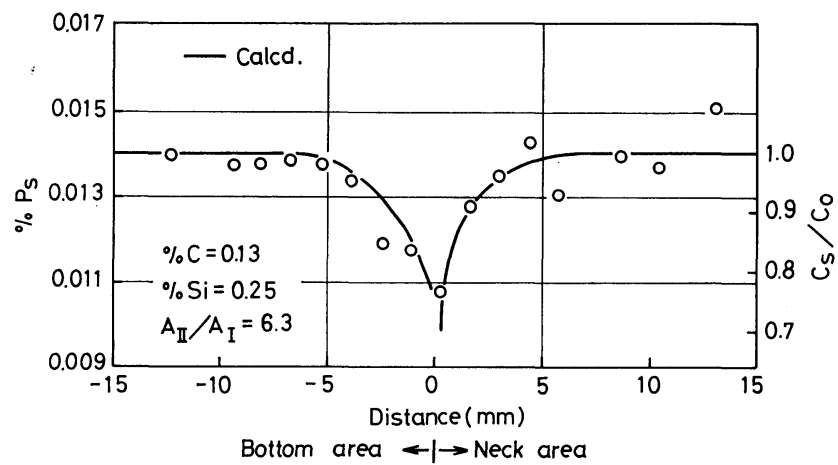

Fig. 10. Concentration distribution of phosphorus in a solidified specimen (coil speed: $12 \mathrm{~mm} / \mathrm{min}$ ). the length of liquid-solid layer, and then experiments on solute segregation were carried out.

\section{Experimental Results and Discussion}

Figure 7 shows a typical curve of temperature change during solidification. Using the correlation of Hirai et al., ${ }^{12)}$ liquidus and solidus temperatures are calculated to be 1533 and $1492{ }^{\circ} \mathrm{C}$, respectively. The solidification rate has a tendency to increase with the progress of solidification. However, similar solidification rates, 5.6 and $5.0 \mathrm{~mm} / \mathrm{min}$ are obtained in the solidification distance of 25 to $50 \mathrm{~mm}$ for the two rates of coil withdrawal. From these data the local solidification time is estimated to be $75 \mathrm{sec}$ and the length of mushy zone $7 \mathrm{~mm}$, which are used in model calculations.

Typical results for segregation are given in Figs. 8 to 10 for phosphorus and in Figs. 11 and 12 for carbon. In the figures calculated curves are also plotted for comparison. A noticeable peak of negative segregation is observed at the section of area reduction in the solidified sample. It is seen from Figs. 11 and 12 that carbon concentration in the neck portion is somewhat lower compared with that in the bottom portion. This is considered to be due to carbon removal from the melt to the inert atmoshere during solidification. Figures 10 and 12 illustrate the results for the case of silicon addition of $0.25 \%$. No clear effects of silicon addition on segregation behavior is seen. Photograph 1 shows a typical macrostructure of a solidified sample. A developed den-

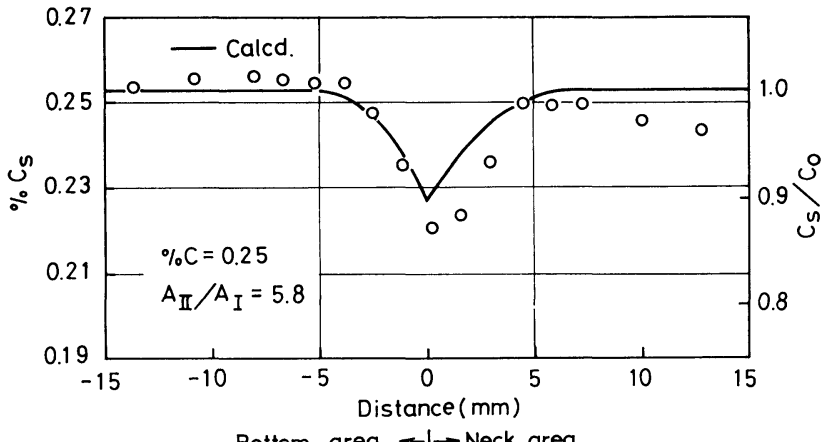

Bottom area $\nleftarrow 1 \rightarrow$ Neck area

Fig. 11. Concentration distribution of carbon in a solidified specimen (coil speed: $12 \mathrm{~mm} / \mathrm{min}$ ).

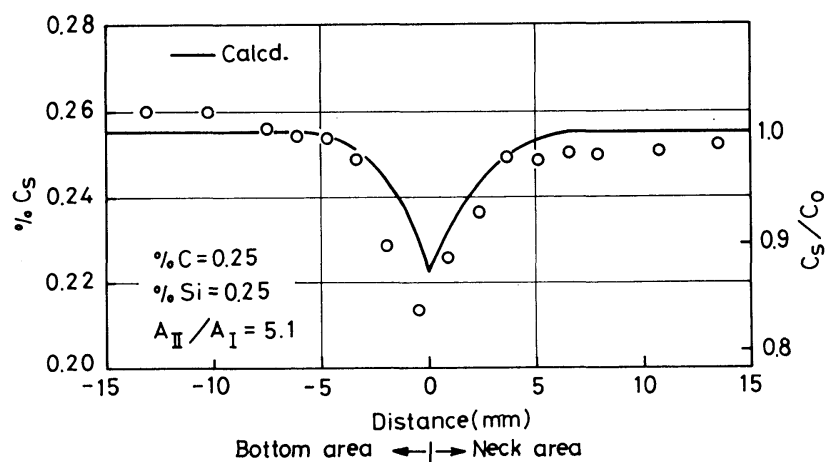

Fig. 12. Concentration distribution of carbon in a solidified specimen (coil speed: $12 \mathrm{~mm} / \mathrm{min}$ ). 


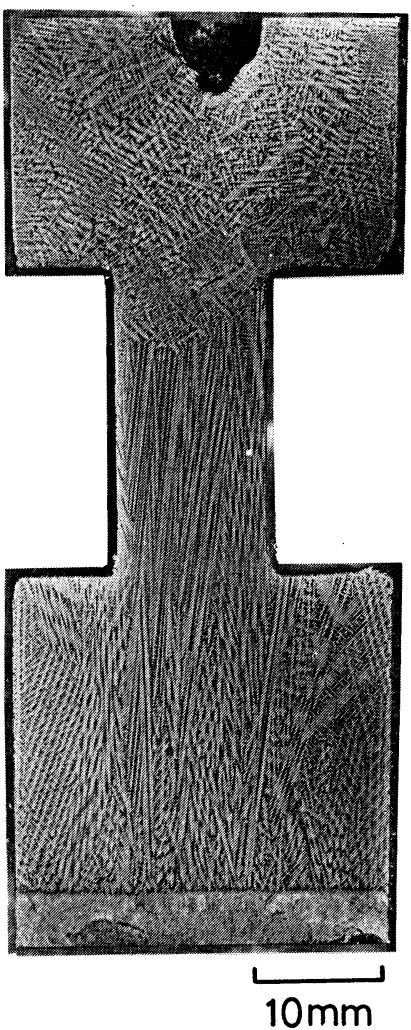

Photo. 1. Macrostructure of a solidified specimen ( $\% \mathrm{G}=$ 0.12 , coil speed: $12 \mathrm{~mm} / \mathrm{min}$ ).

drite structure is observed in the photograph.

It is found from the figures that good quantitative agreement is obtained between calculated and measured composition distribution for both phosphorus and carbon. Further, the fact that segregation peak of phosphorus at the section of area reduction is more remarkable than that of carbon is explained reasonably from the calculations in Figs. 11 and 12. From these findings it is concluded that significant macrosegregation is produced from the flow of solute-rich liquid to feed solidification contraction.

\section{Conclusion}

A mathematical model has been given for solute segregation caused by interdendritic liquid flow to compensate for the solidification contraction. The analysis has been done for segregation of carbon and phosphorus in the iron sample with a discontinuous change in cross-sectional area. A solute-depleted band with a severe peak is predicted to form at the section of area reduction. Negative segregation becomes severe with the increase of $A_{\mathrm{II}} / A_{\mathrm{I}}$. To test the validity of the model a series of experiments has been done. Solute segregation in the specimen is explained reasonably by the present model.

\section{REFERENCES}

1) M. G. Flemings: Scand.J. Met., 5 (1976), 1.

2) K. Suzuki and T. Miyamoto: Tetsu-to-Hagané, 63 (1977),
45 and 53.

3) S. Asai, T. Sahara and I. Muchi: Tetsu-to-Hagané, 63 (1977), 1512

4) H. Kumai, K. Asano, T. Ohashi, E. Nomura and H. Fujii: Tetsu-to-Hagané, 60 (1974), 894.

5) S. Takaishi, T. Komai, K. Noro and Y. Akita: Tetsu-toHagané, 60 (1974), 915.

6) M. C. Flemings and G. E. Nereo: Trans. Met. Soc. AIME, 239 (1967), 1449.

7) M. G. Flemings, R. Mehrabian and G. E. Nereo: Trans. Met. Soc. AIME, 242 (1968), 41.

8) M. C. Flemings and G. E. Nereo: Trans. Met. Soc. AIME, 242 (1968), 50.

9) P. J. Wray: Met. Trans., 5 (1974), 2602.

10) Y. K. Chung, D. Reinish and K. Schwerdtfeger: Met. Trans., 6A (1975), 235.

11) K. Mori, T. Hiraiwa and H. Nomura: Tetsu-to-Hagané, 61 (1975), 2952.

12) M. Hirai, K. Kanamori and H. Mori: The 19th Comm. (Steelmaking), Japan Society for the Promotion of Science (JSPS), Rep. No. 8837, (Dec., 1968).

\section{Appendix}

Derivation of $E q .(8)$

Equation (4) is rewritten:

$$
\frac{\partial}{\partial t}(\overline{\rho c})=-c_{\mathrm{L}} \nabla \rho_{\mathrm{L}} f_{\mathrm{L}} \boldsymbol{V}-\rho_{\mathrm{L}} f_{\mathrm{L}} \boldsymbol{V} \nabla c_{\mathrm{L}}
$$

Substitution of Eq. (5) into the above equation gives: where,

$$
\frac{\partial}{\partial t}(\overline{\rho c})=c_{\mathrm{L}} \frac{\partial \bar{\rho}}{\partial t}-\rho_{\mathrm{L}} f_{\mathrm{L}} V \nabla c_{\mathrm{L}}
$$

where,

$$
\begin{gathered}
\bar{\rho}=\rho_{\mathrm{S}} f_{\mathrm{S}}+\rho_{\mathrm{L}} f_{\mathrm{L}} \ldots . \\
\overline{\rho c}=c_{\mathrm{S}} \rho_{\mathrm{S}} f_{\mathrm{S}}+c_{\mathrm{L}} \rho_{\mathrm{L}} f_{\mathrm{L}} .
\end{gathered}
$$

Substituting $c_{\mathrm{S}}=k c_{\mathrm{L}}$ and $f_{\mathrm{S}}+f_{\mathrm{L}}=1$ into Eq. (A-4) yields :

$$
\overline{\rho c}=k c_{\mathrm{L}} \rho_{\mathrm{S}}\left(1-f_{\mathrm{L}}\right)+c_{\mathrm{L}} \rho_{\mathrm{L}} f_{\mathrm{L}}
$$

Differentiating Eq. (A-5) and rearranging give:

$$
\begin{aligned}
\frac{\partial}{\partial t}(\overline{\rho c})= & k \rho_{\mathrm{S}} \frac{\partial c_{\mathrm{L}}}{\partial t}+c_{\mathrm{L}}\left(\rho_{\mathrm{L}}-k \rho_{\mathrm{S}}\right) \frac{\partial f_{\mathrm{L}}}{\partial t} \\
& +f_{\mathrm{L}}\left(\rho_{\mathrm{L}}-k \rho_{\mathrm{S}}\right) \frac{\partial c_{\mathrm{L}}}{\partial t}+f_{\mathrm{L}} c_{\mathrm{L}} \frac{\partial \rho_{\mathrm{L}}}{\partial t}
\end{aligned}
$$

Substituting Eqs. (A-3) and (A-6) into Eq. (A-2) yields :

$$
\begin{aligned}
& \frac{\partial c_{\mathrm{L}}}{\partial t}\left(k \rho_{\mathrm{S}}+\rho_{\mathrm{L}} f_{\mathrm{L}}-k \rho_{\mathrm{S}} f_{\mathrm{L}}\right)=\left(-\rho_{\mathrm{S}} c_{\mathrm{L}}+k \rho_{\mathrm{S}} c_{\mathrm{L}}\right) \frac{\partial f_{\mathrm{L}}}{\partial t} \\
& -\rho_{\mathrm{L}} f_{\mathrm{L}} \boldsymbol{V} \nabla c_{\mathrm{L}}
\end{aligned}
$$

Rearrangement of Eq. (A-7) gives Eq. (8)

$$
\frac{\partial f_{\mathrm{L}}}{\partial c_{\mathrm{L}}}=-\frac{k+\{1-\beta-k+(1-\beta) \boldsymbol{V} \cdot \nabla T / \varepsilon\} f_{\mathrm{L}}}{(1-k) c_{\mathrm{L}}}
$$

where, $1-\beta=\rho_{\mathrm{L}} / \rho_{\mathrm{S}}$. 